\title{
Science and Society in Dialogue About Marker Assisted Selection
}

\author{
Marianne Benard • Huib de Vriend • \\ Paul van Haperen • Volkert Beekman
}

Accepted: 4 September 2009/Published online: 30 September 2009

(C) The Author(s) 2009. This article is published with open access at Springerlink.com

\begin{abstract}
Analysis of a European Union funded biotechnology project on plant genomics and marker assisted selection in Solanaceous crops shows that the organization of a dialogue between science and society to accompany technological innovations in plant breeding faces practical challenges. Semi-structured interviews with project participants and a survey among representatives of consumer and other nongovernmental organizations show that the professed commitment to dialogue on science and biotechnology is rather shallow and has had limited application for all involved. Ultimately, other priorities tend to prevail because of high workload. The paper recommends including results from previous debates and input from societal groups in the research design phase (prior to communication), to use appropriate media to disseminate information and to make explicit how societal feedback is used in research, in order to facilitate true dialogue between science and society on biotechnology.
\end{abstract}

Keywords Dialogue - Biotechnology · Marker assisted selection · NGOs · Science communication - Science policy

\footnotetext{
M. Benard $(\bowtie)$

Athena Institute for Research on Innovation and Communication in Health and Life Sciences, Faculty of Earth and Life Sciences, Vrije Universiteit Amsterdam, De Boelelaan 1081, 1081 HV Amsterdam, The Netherlands e-mail: m_benard@live.nl

H. de Vriend

LIS Consult, Hogesteeg 9, 3972 JS Driebergen, The Netherlands

P. van Haperen

Methodische Ethiek en Technology Assessment (META), Wageningen University and Research Centre (WUR), Hollandseweg 1, 6706 KN Wageningen, The Netherlands

V. Beekman

Agricultural Economics Research Institute (LEI), P.O. Box 29703, 2502 LS The Hague, The Netherlands
} 


\section{Introduction}

Modern biotechnology, understood as the development and application of molecular biology knowledge and technologies in plant breeding, is a regular source of contention. The use of genetic modification has lead to fierce debates in Europe, resulting in severe restrictions set on experiments with and market introduction of genetically modified plants (Lassen et al. 2002; Torgersen et al. 2002). These debates have demonstrated that innovation in plant biotechnology has to address two ethical questions. The first question is directly related to the technology, and raises the issue of whether humankind should be allowed direct intervention in given biological processes. The second question is related to decision making in innovation processes, and focuses on how society can use and control the potential of a technology that can significantly have an impact on our socio-economic environment (Dyson and Harris 1994; Murphy 2007). Scientists and policy makers are increasingly convinced that technological innovations need to be accompanied by a dialogue between science and society that is true to the context and content of the developments (Goven 2006).

Today, genomics research ${ }^{1}$ is providing us with an avalanche of data and information that is opening up new horizons for biotechnological innovations in plant breeding. Marker assisted selection (MAS) is one of these new opportunities, making it possible to speed up conventional breeding, as quantitative traits can be traced directly in the genome of the seedlings with the aid of markers (Collard and Mackill 2007). Although MAS is just a detection tool, and is therefore fundamentally different from genetic modification, there are three reasons why this technology could be easily associated, if not confused, with genetic modification, which is a contested technology. First, genetic modification is also used during research to establish promising pathways, to test hypotheses on quantitative traits and to develop suitable markers. Second, the very same plant genomics knowledge that MAS is based on can be used to develop new applications of genetic modification. Finally, MAS is one of a range of relatively novel molecular tools that link genomics knowledge and biotechnological innovation, causing the classic dichotomy between genetic modification and other techniques to become increasingly vague. With innovations in biotechnology it has, for example, become possible that genetic modification is used as one step in the creation of plants or fruits that themselves no longer contain any genetically modified material. This poses the question of whether the public still has the opportunity to make a free and informed choice when it concerns food products made with these technologies (Lammerts van Bueren et al. 2007). So, it is reasonable to expect that public concerns raised in the past might be raised again. For this reason a proper science-society dialogue seems warranted.

\footnotetext{
${ }^{1}$ Genomics is the study of the entire genome of organisms. It encompasses the determination of the DNA sequence and related biological functions. DNA sequencing technologies, which are evolving rapidly in terms of speed and costs, and identification of DNA sequences and expression products (proteins) with the help of micro arrays and bioinformatics are important tools. Genomics also includes the large scale study of proteins in a cell type or tissue (proteomics) and the systematic study of the unique chemical fingerprints that specific cellular processes leave behind, specifically the study of their small molecule metabolite profiles (metabolomics).
} 
One of the major lessons from the public debates about genetic modification in Europe has been that communication is pivotal for the public acceptance of biotechnology (Schenkelaars and De Vriend 2008). Another lesson has been that this communication should not have the character of a one-way flow of information from biotechnologists and food scientists (and producers and regulators) towards hitherto ignorant consumers. Such a one-way communication strategy is based on the deficit model. This model explains public resistance to biotechnology as an effect of lacking knowledge, and thus assumes that information in itself would create public acceptance of these innovations. Since this strategy has proven to be ineffective, a shift towards dialogical strategies was observed in the mid 1990s (Biotechnology and the European Public Concerted Action Group 1998). The rather generally accepted opinion is that biotechnology needs to be accompanied by a dialogue ${ }^{2}$ between public, politics, and science to shape the goals of innovation. At the core of this need for dialogue is the idea that the public must be involved in discussions and decisions to ensure societal acceptance on what biotechnology innovations should proceed and under which conditions they could be implemented (Klüver et al. 2000; Tait 2001; Jasanoff 2003; Wilsdon and Willis 2004). The ideal dialogue between science and society is proactive and enables scientists to engage in a discussion with the public prior to the development of biotechnology applications (Frewer et al. 2004; Beekman et al. 2008).

The pursuit of a dialogue between science and society with respect to biotechnology has also been picked up by European research and funding policies for biotechnology (European Commission 2002). ${ }^{3}$ However, a case study of a European project about plant genomics research and marker assisted selection in

\footnotetext{
${ }^{2}$ Literally, a conversation between two or more people (from the Greek dia and logos). Also "engagement in an exchange of ideas and opinions" or "a discussion between representatives of parties to a conflict that is aimed at resolution" (Merriam-Webster). In other words, interchange and discussion of ideas or views. This is different from traditional education or dissemination of information, sending messages, which is unidirectional. An effective dialogue is a mutual learning process, exchanging and adjusting arguments.

${ }^{3}$ The Commission states that "societal scrutiny and dialogue should accompany and guide the development of biotechnology and biotechnology" (p. 19) and continues that biotechnology has "given rise to significant public attention and debate. The Commission welcomes this public debate as a sign of civic responsibility and involvement. Biotechnology should continue to be accompanied and guided by societal dialogue. Dialogue in our democratic societies should be inclusive, comprehensive, well informed and structured. Constructive dialogue requires mutual respect between participants, innovative approaches, and time. It should be structured in agreement with stakeholders to allow progress, for example in the provision of better information and mutual understanding. Experience also shows how important it is that dialogue takes place at the local and national levels, as well as internationally, and the Commission invites Member States and local actors to take relevant initiatives. Dialogue should be open for all stakeholders. Public authorities should help to ensure participation by stakeholders with limited resources. Economic operators, industry and users, who have economic interests at stake, as well as the scientific community bear a particular responsibility for active participation. The Commission invites these parties to respond to public concerns, for example through transparency of their visions, policies and ethical standards. Relevant public information is essential for meaningful dialogue. Providing it requires focused and proactive efforts. It is especially important that the information needs formulated by the broad public are taken seriously and responded to. We shall also strive for a balanced and rational approach, distinguishing between real issues, on which we must act, and false claims" (ibid.).
} 
tomato and potato breeding (EU-SOL) shows that the organization of such a science and society dialogue faces several practical challenges.

\section{EU-SOL-Characteristics and Communication}

EU-SOL (European Union Solanaceae) is a large research project funded by the Sixth Framework Programme of the European Union. It engages a network of life scientists from a variety of institutions in Europe plus Argentina, Israel and South Africa. The emphasis of EU-SOL is on screening and mapping diversity within the plant family Solanaceae. The biodiversity of Solanaceae is enormous and still underexploited. This diversity is used in the project to enrich the genetic basis of cultivated plants. Therefore, a core collection of about 7,000 tomato lines, including some wild relatives, has been created. All these tomato plants, and a number of potato lines, are screened at phenotypic and genotypic levels. Furthermore, the project aims at providing genetic knowledge necessary for the development of high quality solanaceaous crops, primarily focusing on tomato, secondly on potato, and finally on pepper and eggplant. The improved quality will be seen in the development of plants containing new traits that are of benefit to consumers, processors, and producers.

The vast majority of interesting traits in plants are not controlled by a single gene but by a number of genes plus environmental conditions. Sets of genes responsible for a certain characteristic are named quantitative trait loci (QTL). ${ }^{4}$ Unique recognizable sequences of DNA, typically associated with QTL can be identified and are called molecular markers. Marker assisted selection (MAS) is based on the use of these molecular markers, which allows the identification of QTL in plants. MAS improves the speed and possibilities of classical breeding, since transferring and combining genes can now happen at a rate and with a precision not previously possible. The focus of the project is thus on developing molecular tools such as MAS, which can lead to genetically improved varieties without using the controversial genetic modification techniques and with plant material that exclusively originates from the Solanaceae family. This does not mean that genetic modification is not used in the project. To effectively identify QTL and to develop appropriate markers, genetic modification is still used as a research tool. (www.eu-sol.wur.nl/about_eu-sol.php).

Although EU-SOL has as its main aim the development of high quality crops, EU-SOL, in line with EU strategy, also contains work packages including communication activities that are an integrated part of the project. Since improvement of consumer-traits, such as organoleptic quality (taste, odor, consistency) and health

\footnotetext{
${ }^{4}$ Quantitative trait loci (QTL) are stretches of DNA that are closely linked to the genes that underlie the continuous traits (traits that vary continuously and could have any value within a range such as height). They are often found on different chromosomes. Knowing the number of QTLs that explains variation in the phenotype trait tells us about the genetic architecture of a trait. It may tell us that a specific trait is controlled by many genes of small effect or by a few genes of large effect. QTLs can be used to identify candidate genes underlying a trait. Once a region of DNA is identified as contributing to a phenotype, it can be sequenced. The DNA sequence of any genes in this region can then be compared to a database of DNA for genes whose function is already known.
} 
related traits, are important objectives of the project, one part is specifically aiming at consumers. ${ }^{5}$ Other stakeholders, such as NGOs and organizations of growers are also focus points for dissemination of information. Consumer organizations are thought to be important links between research on biotechnology and consumers. Information about food and biotechnology provided by these organizations is usually well trusted by the public (Gaskell et al. 2006). Finally, these organizations are assumed to have the ability to link biotechnology to consumer products and to bridge the gap between science and society. Besides informing these target groups about the goals and methods of EU-SOL, a dialogue was planned in which consumer organizations have the possibility to discuss the aims and methods of EU-SOL and provide feedback (www.eu-sol.wur.nl/about_eu-sol.php).

\section{Methodology}

To create a basis for dialogue between the partners in EU-SOL and target groups, including consumer and non-governmental organizations, opportunities, and bottlenecks for prospective EU-SOL communication activities had to be identified. What would be the similarities and differences between the views, opinions, and values of the project partners and those of the target groups when addressing the aims, methods, and communication strategies of EU-SOL?

Twenty EU-SOL project partners, representing a variety of countries and institutes involved, were interviewed in a semi-structured way. Attention was given to the ideas partners have about the aim and usefulness of dialogue, the framing of genomics, and the wish for feedback from consumers, consumer organizations, and other stakeholders. The aim of these interviews was to get a qualitative picture of the content and variety of views and opinions about the necessity for a societal dialogue about the EU-SOL project.

The results of these interviews were used as input for a second qualitative survey among consumer organizations and other target groups throughout Europe about their own organization, aims of EU-SOL, communication, and genomics. It was decided to approach all 41 consumer organizations that are members of the Bureau Européen des Unions de Consommateurs (BEUC). BEUC is the European association of consumer organizations and one of the main consumer lobbying organizations in Brussels.

\section{Results: Interviews with Project Partners}

\section{Communication Process}

A first result from the 20 interviews with partners in EU-SOL was that, notwithstanding the whole public debate about genetic modification, about half of

\footnotetext{
5 Input from European consumer organizations on societal issues related to this project is an important aspect as well as frequent provision of information to NGOs and the public about the progress of the project and to the project related developments in science and society. Societal aspects such as GMO versus genomics and conventional versus organic approaches will be addressed by public participation, awareness, and outreach (www.eu-sol.wur.nl/about_eu-sol.php).
} 
the interviewees had not given communication with the broader public much thought before the interview. Furthermore, most partners had only occasional contact with stakeholders. Nevertheless, almost all respondents expressed a wish to develop a good and active dialogue with society and thought the public should be better informed about and more aware of the possibilities of marker assisted selection in plant breeding.

Topics that were mentioned to communicate about in a science-society dialogue included facts and myths about biotechnology, (biotechnological) research and development, and the possibilities and limitations of genomics. The aim of this communication would be to raise understanding and reassure confidence among the public at large. It was thought that more public awareness of problems and challenges in agriculture and food production could lead to a better understanding of the goals of biotechnology.

A small number of respondents expressed a certain cynicism that providing information about EU-SOL would be misused or misinterpreted to serve partisan positions. Bad experiences during the previous public debates on genetic modification were given as reason for this cynicism. Some partners felt that stakeholders, including governments and NGOs, should take responsibility in supporting new technologies in the field of life sciences.

Some partners also expressed skepticism about the requirement for dialogue within EU-SOL as a research project. They thought that this was not the right moment to engage target groups, since the design stage of the project has passed already and results will only come after many years. Furthermore, this emphasis on communication was seen to serve political interests and as an artefact of funding rules and regulations.

Various partners recognized that science-society dialogue has not been optimal within the context of EU-SOL. Several ideas were voiced to improve this dialogue between science and society: information should be positive, scientists should be more transparent, and scientists should alter their detached attitude and sometimes arrogant approach. On a more practical note, it is suggested that a wider use of publications in more accessible and popular papers and magazines and direct communication could help to bridge the gap between scientists and consumers. Although receiving societal feedback was uncommon for most partners, it has to be acknowledged that respondents were open to receive and use feedback from other stakeholders. They were convinced that feedback would ultimately result in better technological applications and thus to better services for society.

\section{Communication Contents}

The EU-SOL partners by-and-large argued that it is important to explain biotechnology and the subtleties of MAS and genomics in comprehensible language to the general public and stakeholder organizations, because MAS and genomics are perceived to remain as difficult and value-laden as biotechnology, specifically genetic modification, itself. When describing the difference between MAS, genomics, and genetic modification, the respondents seemed to make a clear distinction between their own point of view and what they expected the views of 
consumers and consumer organizations to be. When prompted about this distinction, the answers of the interviewees suggested a divergence among EU-SOL partners. A small majority of respondents suggested that there is probably little difference between their own and consumer views: whatever the application, it is all a form of biotechnology that includes active intervention in the design of plants or species. Others strongly disagreed with this majority position. According to them, MAS is not an active intervention in the design of the plant, while genetic modification is. Unfortunately, in the project partners' anticipation, consumers seem to conflate MAS and genetic modification. A third position was to take a more constructive stance on the important and meaningful distinction between MAS and genetic modification. These respondents thought that it should be possible to convince the public that exploiting genomics knowledge through MAS is more acceptable than genetic modification, as the results are achieved through conventional breeding and not through direct manipulation in the genetic make-up of the plants. Finally, some respondents, above all, emphasized the need for increased education of the public to raise understanding and appreciation of the difference between MAS and genetic modification.

All partners agreed with the choice to focus on MAS in EU-SOL and did not expect that MAS will cause much of a public debate. The respondents differed most in their views about the amount and contents of information to be disseminated by EU-SOL. Almost all respondents thought that their colleagues would agree with their views, while during the interviews quite divergent opinions were raised.

\section{Results: Survey of Consumer and Non-governmental Organizations}

\section{Communication Process}

All 41 member organizations of BEUC were approached several times, however only fourteen consumer organizations responded to the questionnaire. Forty other target groups, including environmental organizations, growers, and consultancies, were approached but only seven of these organizations were eventually willing to respond to the survey. These seven respondents were three tomato growers, two farmers' organizations, one commercial cooperative, and one environmental organization.

In general, the impression gained is that the majority of the consumer and nongovernmental organizations are not very open to new information or topics introduced by a research project like EU-SOL. Several organizations indicated to be interested in new developments around genetic modification but not in MAS or the use of genomics in plant breeding. Furthermore, it was hard to get in touch with the right person or representative, and the respondents usually indicated that they had little time to answer the questions. Reasons given by consumer organizations that did not answer the questionnaire were lack of expertise, lack of time, no direct benefit for consumers, standard rules to only answer questionnaires from other consumer organizations, and to only participate in questionnaires for projects in the design stage. 
The participating organizations valued dialogue with scientists working on biotechnology in agriculture and food production. Furthermore, the desire to influence research priorities through such a dialogue was high. However, organizations were by-and-large not satisfied with their experiences with such dialogue and they argued that the exchange of information between science and society needs to be improved.

Many problems as well as solutions were given with respect to science-society dialogue about biotechnology. It was commented that it is not easy to stay up-to-date with scientific developments through reading scientific literature. Furthermore, there is an overwhelming amount of information, which is very often not clearly presented. Free Internet newsletters were thought to be a good information outlet. Another comment was that the initial stage in any dialogue is difficult, since trust between the parties to the dialogue is pivotal. One view expressed is that scientists are very often perceived to be paid by the industry, which creates the impression that they are not neutral.

\section{Communication Contents}

The consumer organizations that responded to the questionnaire clearly had divergent opinions about the usefulness of the uncovering of the genome of fruits and vegetables, while most other target groups had a more positive attitude. The consumer organizations had different levels of expertise with respect to developments in plant breeding. The majority of the respondents (14 out of 21) said that they do not have sufficient knowledge and there seemed to be some confusion about different applications of biotechnology. Most respondents (16 out of 21) nevertheless thought that there is an important difference between marker assisted selection and genetic modification and that this difference would also be important for consumers.

Support for the use of genomics information depended on the type of technology that it would be applied for. While the use of genomics information for MAS was supported by a small majority (10 out of $21^{6}$ ) of the target groups, the use for genetic modification still received very low support (5 out of 21). Asked about different objectives, almost all respondents (16 out of 21) supported the use of genomics knowledge for conservation of biodiversity, optimization of cultivation methods, and speeding up of classical breeding. The respondents were also asked about what they thought that knowledge of uncovering the genome was most likely to be applied to. MAS and genetic modification were mentioned by almost all respondents. Optimizing cultivation methods and speeding up of classical breeding were expected by a small majority of the respondents. Only a minority thought that it would be used for the conservation of biodiversity. A remarkable feature was the difference between the expectations of participants between what they thought genomics information should be used for and what they expected it would be used for. While only 5 respondents thought it should be used for genetic modification, 14 respondents thought that eventually it would be used for genetic modification.

\footnotetext{
$\overline{6}$ Ten interviewees supported this, 5 had no opinion, 6 were against.
} 


\section{Comparative Analysis}

\section{Communication Process}

Discussions among project partners and consumer organizations are very limited. They seem to restrict discussion to their own communities (i.e., they do not talk to each other). Only a few project partners had direct contact with target groups and primarily discussed scientific topics among themselves. Likewise, consumer organizations preferred communication with other consumer organizations. Despite this low level of interaction, both project partners and target groups thought that dialogue between the two groups is important. A majority of the target groups would like to influence research priorities and project partners would welcome such feedback.

Target groups thought that communication with scientists and access to results of research in the domain of biotechnology for agriculture and food production is insufficient. Several project partners stressed the necessity to improve the image of science, scientists, and biotechnology but some others were skeptical about communication. Project partners' experiences in the earlier debates about genetic modification had been negative. According to the project partners, several NGOs developed an unbalanced, negative attitude towards genetic modification, which was based on a limited picture of the pros and cons. They worried that something similar might happen in the case of EU-SOL.

Project partners and target groups made several suggestions to improve sciencesociety dialogue. A broader use of scientific papers/publications was suggested by both groups. Other suggestions made by target groups-e.g., free Internet newsletters, better collaboration between media and scientists and a trustworthy intermediary to facilitate dialogue — could also be considered. Several partners suggested direct communication with the public through schools and universities. They argued that the public should be encouraged to become more aware of the importance of biotechnology in daily life. Some project partners thought that information should focus on benefits but target groups largely disagreed with this idea, since they wanted to be informed about the whole picture and not just about the benefits of biotechnology. Project partners also suggested giving attention to facts and myths about biotechnology, technological development in general, and the possibilities and limitations of genomics.

Hence, although both project partners and consumer organizations in this study highly valued science-society dialogue, interaction is not yet optimal and hardly any steps for specific prospective actions have been taken. The most important reason for this lack of initiative seems to be that contact between parties is rather limited as a result of structural factors like high workload, low sense of urgency, and the institutional output assessment of scientists and policy officers (papers, lectures, lobby results, media attention). BEUC emphasized the importance of two-way communication but provided no specific ideas on how this could work.

\section{Communication Contents}

Several project partners emphasized that EU-SOL does not include the development of genetically modified organisms (GMOs). Many partners thought that the public 
would have difficulty understanding the difference between MAS and genetic modification. In contrast, they believed that target groups would understand and appreciate the difference between the two technologies. Project partners believed that the acceptance of MAS would not be an issue. Different levels of expertise existed among target groups and there seemed to be some confusion about the various biotechnologies. Nevertheless, both groups thought that there is a difference between MAS and genetic modification. They also thought that this difference would be important for consumers. However, a large number of consumer organizations thought that the knowledge of the genome should not be applied to MAS and this opinion was not based upon lack of knowledge or a conflation between MAS and genetic modification. A possible explanation is that most target groups believed that the uncovering of the genome would be used primarily for genetic modification. Several consumer organizations were therefore skeptical about the aims of EU-SOL. This sometimes caused resistance to MAS and even towards the uncovering of the genome.

\section{Conclusions and Recommendations}

EU-SOL is not unique in including communication activities, through work packages, as an integrated part of the project, usually run by a group of social scientists, to focus on communication and interaction with society. The study of EUSOL shows that this is not good enough as an attempt to facilitate science-society dialogue about biotechnology.

From the interviews it appears that scientists themselves are insufficiently aware of the different views within their own community about the purpose of this dialogue. It is important that these differences are made explicit within the project and that there is consensus building about which perspectives could be used and presented in dialogue with society at large. The stakeholder questionnaire shows that the respondents value science-society dialogue, argued that improvements to this dialogue were necessary, and emphasize the need to influence research priorities. However, it also showed that a majority of the responding organizations did not seem to be willing to invest in improving this dialogue for a project that has been established already.

So, why does it seem to be so difficult to initiate a dialogue starting from different perspectives and before the targets have been set? It is not for a lack of guidelines and theory on setting up a proper science-society dialogue. If anything, the problem would rather be to pick the right tools from a whole plethora of available approaches (see, e.g., Beekman and Brom 2007; De Cock Buning et al. 2008).

The so-called Collingridge dilemma poses that it is always too early or too late for a good science-society dialogue (Collingridge 1980). ${ }^{7}$ A proper response,

\footnotetext{
7 Collingridge (1980) formulated this dilemma in terms that combined problems of information and power. The information problem is related to the fact that impacts cannot easily be predicted until the technology is extensively developed and widely used. At the same time, control or change is difficult when the technology has become entrenched.
} 
however, would be to argue that the Collingridge dilemma is false. Once it has been acknowledged that societal discussions need to accompany the whole life cycle of biotechnology development, it is never too early or too late for dialogue. Timing merely determines what could or should be discussed.

The above line of reasoning does not need to start from the implausible assumption that research and development $(\mathrm{R} \& \mathrm{D})$ are activities with predictable outcomes and steps that can be planned well ahead. In reality, R\&D usually has the characteristics of a learning process, with numerous feedback loops, adaptations, and sometimes surprising results. In that case, dialogue is still worthwhile, provided that certain conditions are met. Intervening in an ongoing process of $R \& D$ is more difficult than discussing a clear research agenda in the starting phase, which makes transparency of the process a necessity. It should also be absolutely clear what opportunities are left to influence the R\&D process and how the feedback of the stakeholders will be dealt with.

A good dialogue would at the least need the following activities to be included in such research projects:

- Time for discussion among the participating scientists about the goals and anticipated outcomes of their research before the project is fully defined;

- Time for discussion between participating scientists and consumer and societal representatives about the goals and anticipated outcomes of the research before the project is fully defined.

The above suggestion is very practical and can be implemented in the current design of life science research projects. All it requires is budgets that cover the time spent by all project participants on discussions about project goals and outcomes and also for the time spent by consumer and societal representatives on these discussions.

But is this sufficient to address the ethical issues concerning acceptable interventions in biological processes and decisions in innovation processes effectively? Or do we need more structural changes in the relation between science and society in order to come to meaningful communication activities? The BEUC stated in one of its policy papers: "Only an open decision making process that would involve consumers at the earliest possible stage will enable a degree of 'harmony' between science and society. The informing of consumers may not be seen as a one-way information system since we believe that the dialogue with and feedback from stakeholders is of crucial importance" (BEUC 2000). Academics like Wilsdon and Willis (2004) see a role in involving the public and other stakeholders even earlier through advisory panels and consultation exercises during the selection and framing of research programs and thematic priorities. They are calling upon science to "[come to the] recognition that experimentation continues as scientific and technological knowledge diffuses into complex social systems" (p. 61). Goven (2006) points to the need to "let the results of previous dialogues and consultations frame our current ones [...] to enable participants to address current policies in greater detail" (p. 111). And finally, Jasanoff (2003) pleads for a change in "social contract" by questioning the value of peer review as a system of moral scrutiny in comparison to a much more needed public accountability system. This type of 
structural approaches could strike a better balance between societal needs and demands and the technological imperative.

Both recommendations, practical and structural, would require a policy change for the design of biotechnology projects. Goals highlighted in debates about relevant issues such as food quality and sustainable agriculture must be used as a starting point for research proposals. Scientific plus societal criteria for evaluation must be made explicit prior to take off. Societal groups should be actively involved in establishing these criteria and the assessment of research proposals and the evaluation during different stages of the implementation of projects. Finally, research proposals should make explicit how societal feedback will be used in research and include the use of appropriate media to inform the public. Only when science-society dialogue is matured, will it be possible to appropriately address the two ethical questions posed at the start of this paper-permissible intervention in biological processes and use and control of technologies.

Open Access This article is distributed under the terms of the Creative Commons Attribution Noncommercial License, which permits any noncommercial use, distribution, and reproduction in any medium, provided the original author(s) and source are credited. The work of the authors was funded by the FP6 European EU-SOL project number PL 016214.

\section{References}

Beekman, V., \& Brom, F. W. A. (2007). Ethical tools to support systematic public deliberations about the ethical aspects of agricultural biotechnology. Journal of Agricultural and Environmental Ethics, 20,3-12.

Beekman, V., Coff, C., Korthals, M., \& Schipper, L. (2008). Communicating ethical traceability. In C. Coff, D. Barling, M. Korthals, \& T. Nielsen (Eds.), Ethical traceability and communicating food (pp. 277-292). Dordrecht: Springer.

BEUC. (2000). Food safety-BEUC comments on the Commission White Paper. Brussels: BEUC.

Biotechnology and the European Public Concerted Action Group. (1998). Europe ambivalent on biotechnology. Nature, 387, 845-847.

Collard, B., \& Mackill, D. (2007). Marker-assisted selection: An approach for precision plant breeding in the twenty-first century. Philosophical Transactions. Royal Society B, 363, 557-572.

Collingridge, D. (1980). The social control of technology. New York: St. Martin's Press.

de Cock Buning, T., Regeer, B., \& Bunders, J. F. G. (2008). Biotechnology and food-Towards a societal agenda in 100 steps. The Hague: RMNO.

Dyson, A., \& Harris, J. (Eds.). (1994). Biotechnology and ethics. London: Routledge.

European Commission. (2002). Life sciences and biotechnology: A strategy for Europe. Communication from the Commission to the European Parliament, the Council, the Economic and Social Committee and the Committee of the Regions 27. Brussels: European Commission.

FAO. (2003). Marker assisted selection: A fast track to increase genetic gain in plant and animal breeding?. Turin: FAO.

Frewer, L., Lassen, J., Kettlitz, B., Scholderer, J., Beekman, V., \& Berdal, K. G. (2004). Societal aspects of genetically modified foods. Food and Chemical Toxicology, 42, 1181-1193.

Gaskell, G., Stares, S., Allansdottir, A., Allum, A., Corchero, C., Fischler, C., et al. (2006). Europeans and biotechnology in 2005: Patterns and trends. Final report in Eurobarometer 64.3. Brussels: European Commission.

Goven, J. (2006). Dialogue, governance and biotechnology: Acknowledging the context of the conversation. The Integrated Assessment Journal, 6(2), 99-116.

Jasanoff, S. (2003). Technologies of humility: Citizen participation in governing science. Minerva, 41, 223-244. 
Klüver, L., Nentwich, M., Peissl, W., Torgersen, H., Gloede, F., Hennen, L., et al. (2000). EUROPTA, European participatory technology assessment. Participatory methods in technology assessment and technology decision making. Copenhagen: Danish Board of Technology.

Lammerts Van Bueren, E., Verhoog, H., Tiemens-Hulscher, M., Struik, P., \& Haring, M. (2007). Organic agriculture requires process rather than product evaluation of novel breeding techniques. Netherlands Journal of Agricultural Science, 54, 4.

Lassen, J., Allansdottir, A., Liakoupulos, M., Olsson, A., \& Mortensen, A. T. (2002). Testing times: The reception of round-up ready soya in Europe. In M. Bauer \& G. Gaskell (Eds.), Biotechnology-The making of a global controversy (pp. 279-312). Cambridge: Cambridge University Press.

Murphy, D. (2007). Plant breeding and biotechnology: Societal context and the future of agriculture. Cambridge: Cambridge University Press.

Schenkelaars, P., \& de Vriend, H. (2008). Oogst uit het lab, biotechnologie en voedselproductie. Utrecht: Jan van Arkel.

Tait, J. (2001). More Faust than Frankenstein: The European debate about the precautionary principle and risk regulation for genetically modified crops. Journal of Risk Research, 4(2), 175-189.

Tanksley, S. D., Young, D., Paterson, A. H., \& Bonierbale, M. W. (1989). RFLP mapping in plant breeding: New tools for an old science. Nature Bio/Technology, 7, 257-264.

Torgersen, H., Hampel, J., Durant, J., Einseidel, E., Fjaestad, B., Gaskell, G., et al. (2002). Promise, problems and proxies: 25 Years of European biotechnology debate and regulation. In M. Bauer \& G. Gaskell (Eds.), Biotechnology-The making of a global controversy (pp. 21-94). Cambridge: Cambridge University Press.

Wilsdon, J., \& Willis, R. (2004). See-through science: Why public engagement needs to move upstream. London: Demos. 